Case Report

\title{
Response to Plasmapheresis Measured by Angiogenic Factors in a Woman with Antiphospholipid Syndrome in Pregnancy
}

\author{
Karoline Mayer-Pickel, ${ }^{1}$ Sabine Horn, ${ }^{2}$ Uwe Lang, ${ }^{1}$ and Mila Cervar-Zivkovic ${ }^{1}$ \\ ${ }^{1}$ Department of Obstetrics and Gynecology, Medical University of Graz, Graz, Austria \\ ${ }^{2}$ Department of Nephrology, Medical University of Graz, Graz, Austria \\ Correspondence should be addressed to Karoline Mayer-Pickel; karoline.pickel@medunigraz.at
}

Received 16 March 2015; Accepted 8 July 2015

Academic Editor: Eliezer Shalev

Copyright (C) 2015 Karoline Mayer-Pickel et al. This is an open access article distributed under the Creative Commons Attribution License, which permits unrestricted use, distribution, and reproduction in any medium, provided the original work is properly cited.

\begin{abstract}
An imbalance of angiogenic and antiangiogenic placental factors such as endoglin and soluble fms-like tyrosine kinase 1 has been implicated in the pathophysiology of preeclampsia. Extraction of these substances by plasmapheresis might be a therapeutical approach in cases of severe early-onset preeclampsia. Case Report. A 21-year-old primigravida with antiphospholipid syndrome developed early-onset preeclampsia at 18 weeks' gestation. She was treated successfully with plasmapheresis in order to prolong pregnancy. Endoglin and sflt-1-levels were measured by ELISA before and after treatment. Endoglin levels decreased significantly after treatment $(p<0.05)$ and showed a significant decrease throughout pregnancy. A rerise of endoglin and sflt-1 preceded placental abruption 4 weeks before onset of incident. Conclusion. Due to the limited long-term therapeutical possibilities for pregnancies complicated by PE, plasmapheresis seems to be a therapeutical option. This consideration refers especially to pregnancies with early-onset preeclampsia, in which, after first conventional treatment of PE, prolongation of pregnancy should be above all.
\end{abstract}

\section{Introduction}

The antiphospholipid syndrome (APS) is an autoimmune disease characterized by the presence of antiphospholipid antibodies (anticardiolipin antibodies (ACLA), lupus anticoagulants (LA), and $ß 2$-glycoprotein) in the maternal circulation. These antibodies are associated with arterial and venous thromboses and with adverse obstetric outcomes such as recurrent fetal loss, intrauterine growth restriction (IUGR), intrauterine fetal death (IUFD), and preeclampsia [1].

Preeclampsia complicates $1 \%$ to $7 \%$ of all pregnancies and is a leading cause of pregnancy-associated mortality and morbidity in developed countries. Mechanisms suggested to explain APS include thrombosis, vascular and endothelial inflammation, and an imbalance of angiogenic and antiangiogenic placental factors such as endoglin and soluble fmslike tyrosine kinase 1 (sflt-1) [2, 3]. In APS, anti-endothelial cells antibodies lead to endothelial cell injury and apoptosis. The underlying pathophysiology of this disease suggests an imbalance of an angiogenic substances associated with endothelial dysfunction $[4,5]$.
Treatment options for APS, especially in early gestation, are limited and based on low-dose aspirin and low-molecular-weight heparin. Severe cases have been treated with intravenous immunoglobulins (IVIG), corticosteroids, antimalarials, TNF-targeted therapies, and immunomodulatory agents such as pentoxifylline [6].

There is a rationale for extracting of antiangiogenic markers, particularly aPl, via plasmapheresis in patients with severe early-onset preeclampsia [7]. Plasmapheresis has been used successfully in pregnancy for preeclampsia and HELLPsyndrome [8-12], as well as APS [13-19], and has been reported being safe during pregnancy [20].

We report a case of a woman with APS who developed severe preeclampsia at 19-week gestation and was successfully treated with plasmapheresis.

\section{Case Report}

A 21-year-old primigravida with a 4-year history of APS and a history of deep vein thrombosis was admitted to our 
TABLE 1

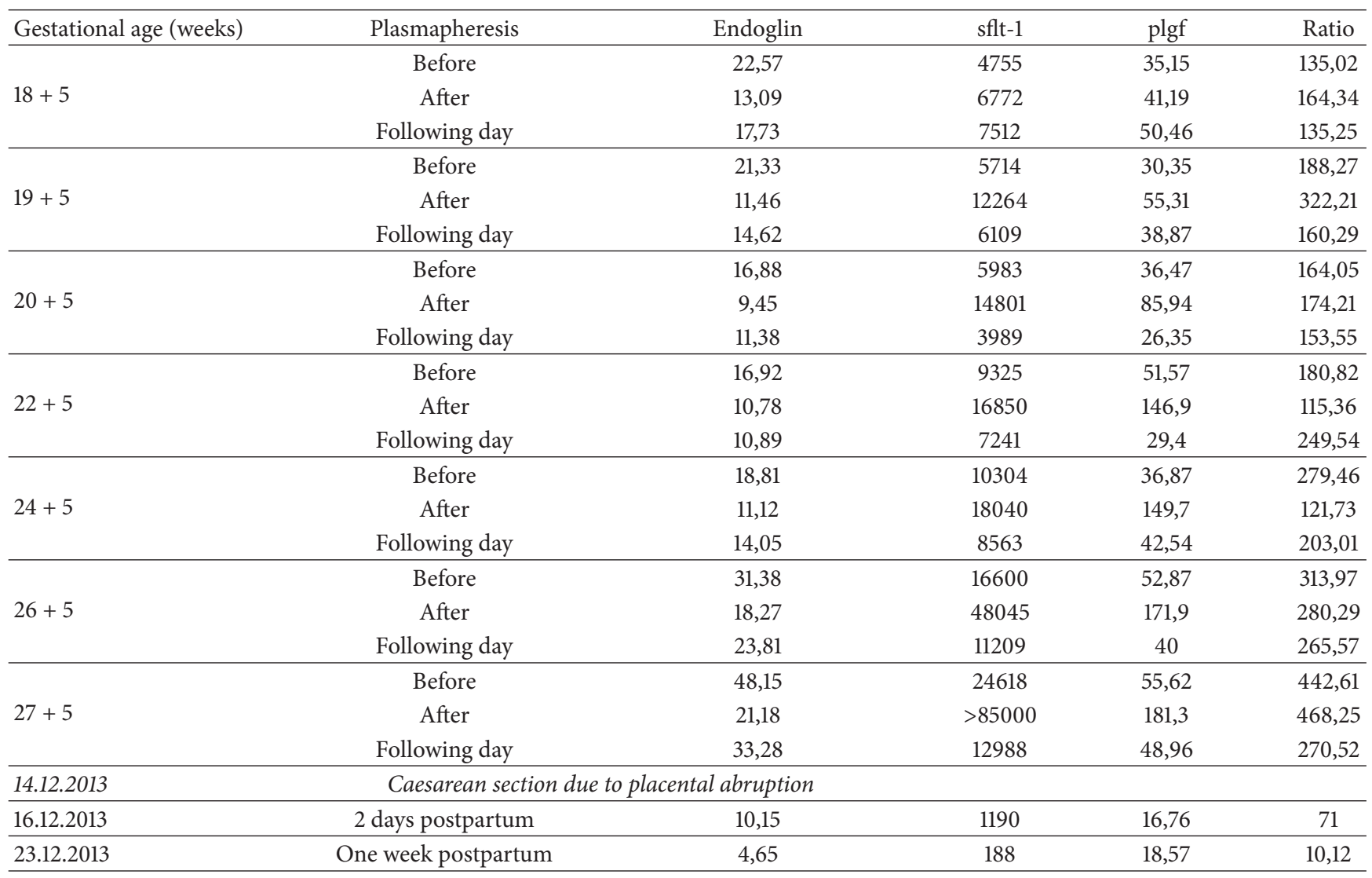

department at $18+3$ weeks' gestation with preeclampsia. Thrombophilia screening showed high titers of aPl: LupusaPTT: $2 \mathrm{sec}$ (normal: -41 sec); Lupus-LA1: $78.2 \mathrm{sec}$ (normal: $-45 \mathrm{sec}$ ); Lupus ratio: 2,24 (normal: -1.30 ). Titers of ACLA and B2-glycoprotein were normal: ACLA-screening: 4, $9 \mathrm{U} / \mathrm{mL}$ (normal $0,0-10$, and $0 \mathrm{U} / \mathrm{mL}$ ); ß2-glycoproteinscreening: $7.9 \mathrm{U} / \mathrm{mL}$ (normal: $<10,0 \mathrm{U} / \mathrm{mL}$ ). Antiphospholipase-a2-receptor antibodies were negative.

The patient was treated with low-molecular-weight heparin (LMWH) $(2 \times 60 \mathrm{mg}$ enoxaparin) from beginning of pregnancy and received aspirin $(100 \mathrm{mg} / \mathrm{d})$.

At 19 weeks, the patient was admitted to the hospital because of suspected preeclampsia. Fetal growth and Doppler studies were normal, with a bilateral notch of the uterine artery. The patient reported pain in the right and left upper abdomen; she denied headache and blurred vision. Platelets were normal (154.000 G/L, normal: 140-440.000 G/L) as was uric acid (2.5 mg/dL, normal: $2.4-5.7 \mathrm{mg} / \mathrm{dL})$. LDH (280 U/L, normal: 120-240 U/L); GPT (110 U/L, normal: $-30 \mathrm{U} / \mathrm{L})$; and GOT (94 U/L, normal: $-35 \mathrm{U} / \mathrm{L}$ ) were increased. There was mild proteinuria ( $330 \mathrm{mg} / 24$ hours). Preeclampsia as confirmed and magnesium sulfate were started. Because of the early onset of the disease, thenormal fetal biometry, and the lack of fetal distress, we decided to recommend plasmapheresis with the intention of prolonging pregnancy.

The first plasmapheresis was performed at 19 weeks of gestation. Clinical symptoms improved immediately; GOT and GPT (GOT: 39 U/L; GPT: 48 U/L) and aPl (Lupus apTT: 20,
Lupus-LA1: 45.2; Lupus ratio: 1.50) decreased. Subsequently plasmapheresis was performed at weekly intervals.

Plasmapheresis was carried out via a catheter placed in the right jugular vein. A plasma filtration technique with Hemaplex BT 900/A Filters (Dideco, Mirandola, Italy) was used. During each treatment session, 3 liters of plasma was removed and continuously substituted with 3,0 liters of solvent-detergent treated standardized pooled human plasma (Octaplas, Octapharma Vienna, Austria). Anticoagulation therapy during plasmapheresis consisted of 3000 IU (international units) heparin administered as intravenous bolus and 1500 IU heparin per hour as continuous infusion.

Shortly before and after every course blood samples were collected and centrifuged by $800 \mathrm{rpm}$ for 10 minutes, sera were portioned in $200 \mu \mathrm{L}$ aliquots and stored at $-80^{\circ} \mathrm{C}$ until measurement. Heparin is known to release sflt- 1 levels into the maternal circulation in vitro and in vivo; therefore, blood samples were also collected one day after plasmapheresis.

A commercial ELISA kit (R\&D Systems Inc., Minneapolis, USA) was used for assaying endoglin according to the manufacturer's protocol.

A commercial ELISA kit (Roche Diagnostics $\mathrm{GmbH}$, Mannheim, Germany) was used for measuring sflt-1 and plgf according to the manufacturer's protocol.

Mean endoglin levels decreased significantly from 25.15 \pm $11.3 \mathrm{ng} / \mathrm{mL}$ (normal: 2.54-7.06 ng/mL) before to $13.6 \pm$ $4.4 \mathrm{ng} / \mathrm{mL}$ after plasmapheresis $(p<0.05)$ (Table 1$)$. sflt-1 levels $(11042 \pm 7213 \mathrm{pg} / \mathrm{mL})$ increased after plasmapheresis 


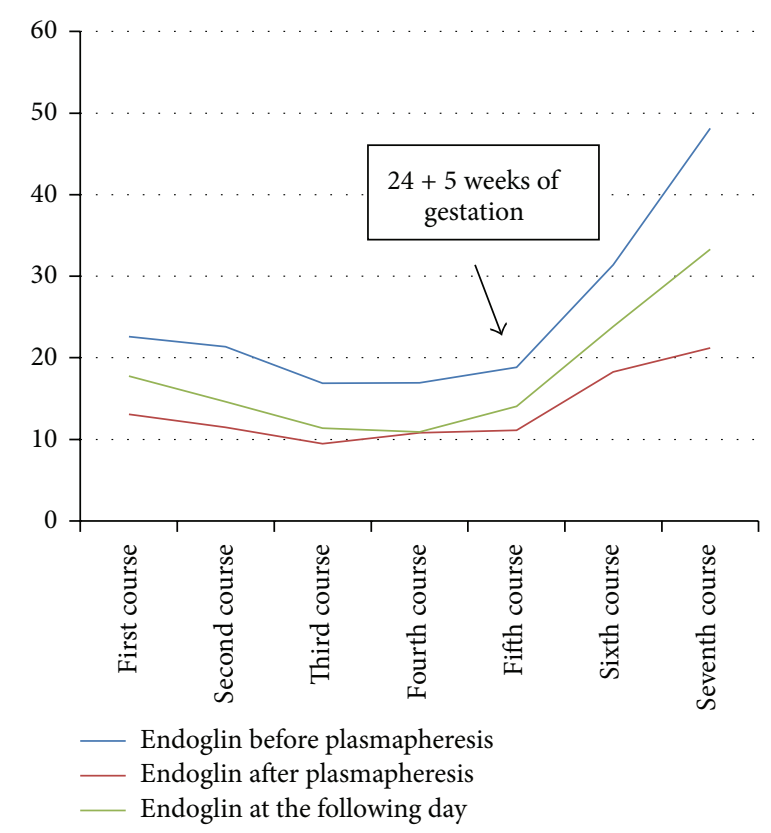

FIGURE 1: Endoglin, sflt-1, and plgf levels measured throughout pregnancy.

$(4742 \pm 28112 \mathrm{pg} / \mathrm{mL})$ due to the effect of heparin releasing sflt-1 into the maternal circulation (Table 1). However, sflt decreased the following day $(8230 \pm 3044 \mathrm{pg} / \mathrm{mL}, p=0.36)$ (Table 1). Mean plgf levels $(42 \pm 10 \mathrm{pg} / \mathrm{mL})$ also increased after plasmapheresis $(118 \pm 57 \mathrm{pg} / \mathrm{mL})$ and decreased the following day $(39 \pm 9 \mathrm{pg} / \mathrm{mL}, p=0.5)$ (Table 1). Endoglin measurements showed a decreasing trend over time, with a nadir $(16.88 \mathrm{ng} / \mathrm{mL}$ before plasmapheresis and $9.45 \mathrm{ng} / \mathrm{mL}$ after plasmapheresis) at $20+5$ weeks of gestation (Figure 1). sflt-1 levels measured before plasmapheresis as well one day after plasmapheresis showed a decreasing trend until the fifth course (24+5 weeks of gestation) (Figure 2). plgf immediately after plasmapheresis showed an increasing trend throughout gestation. The measurements before plasmapheresis as well as at the following day showed a similar trend (Figure 3). All courses were well tolerated; the patient was asymptomatic. Blood pressure was normal, as were platelets, $\mathrm{LDH}$, uric acid, GPT, and GOT.

At $24+5$ weeks, endoglin and sflt- 1 increased (Table 1 ). The patient was asymptomatic. Laboratory workup showed mild thrombocytopenia $(133.000 \mathrm{G} / \mathrm{L})$. Blood pressure was normal. Sonography showed normal fetal growth; Doppler studies of umbilical, cerebral artery, and ductus venosus were normal. There were no signs of placental abruption. Three days after the seventh plasmapheresis, severe vaginal bleeding was noted and an emergency caesarean section was performed. During the procedure, full abruption of the placenta could be noted. There were no signs of coagulopathy; vital signs were stable. A female preterm in stable conditions was delivered (830 g, APGAR: 8/9/9; pH: 7.37).

The patient was transferred to the intensive care unit in stable conditions for observation and retransferred after 2 days. The postoperative/postpartum period was without any complications; endoglin and sflt-1 and plgf and sflt-1/plgf ratio levels returned to normal values (Table 1 ). The patient

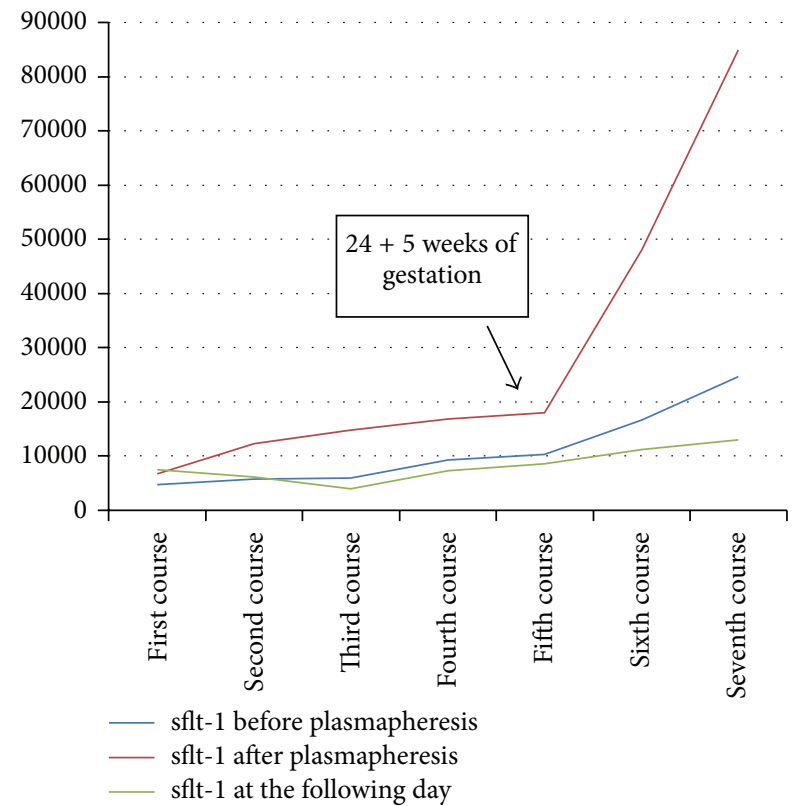

FIGURE 2: sflt-1, measured immediately before and after treatment and at the following day.

could be dismissed after 2.5 weeks. The infant was discharged home at 2 months in stable condition.

\section{Discussion}

We describe a pregnant woman with APS who developed early-onset preeclampsia at $18+3$ weeks' gestation and who was treated with plasmapheresis and developed placental abruption at $27+5$ weeks. Endoglin levels as well as sflt-1 at time of admission were increased. 


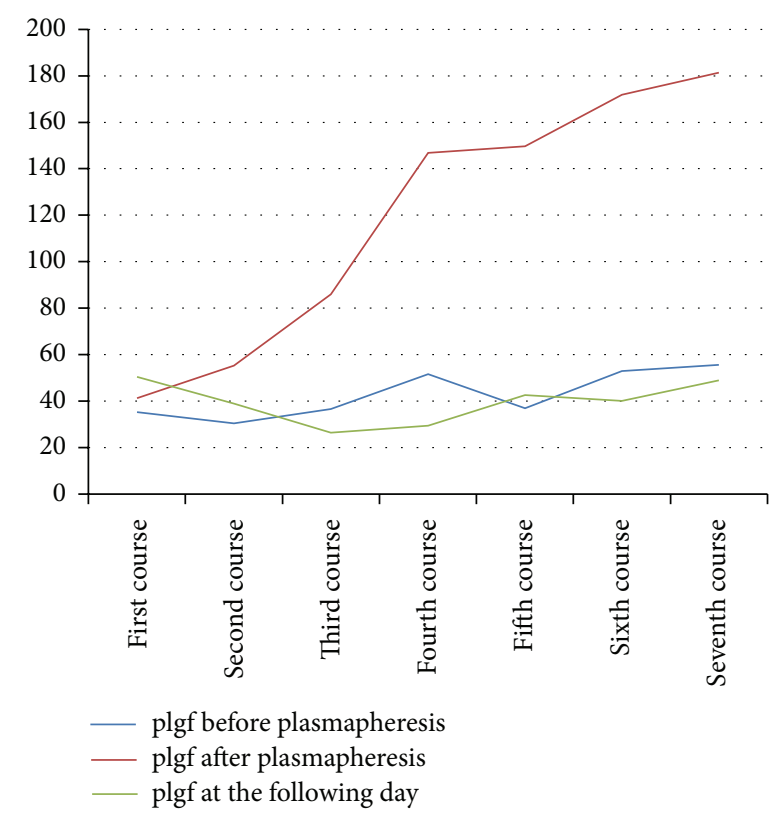

FIGURE 3: plgf, measured immediately before and after treatment and at the following day.

Measurements of endoglin showed a significant decrease after plasmapheresis as well as a decreasing trend throughout gestation until the fifth course $(24+5$ weeks of gestation) and 3 weeks before placental abruption. These findings confirm the involvement of endoglin in the pathophysiology of $\mathrm{PE}$ [21-31], as well as the obvious role of endoglin as marker for placental abruption [32].

Heparin likely has no effect on circulating factors of endoglin [33]. This finding is in contrast to sflt-1, which is known to be released into the maternal circulation by heparin $[34,35]$. However, a recent study of the effect of heparin on circulating levels of sflt-1, sEng, and plgf in pregnant women who required anticoagulation therapy showed no differences of the levels of sflt- 1 and sEng between women who received heparin and the control group. Also treatment with heparin was associated with increased maternal circulatory levels of plgf and a decreased sflt-1/plgf ratio [36].

Endoglin is a transmembrane glycoprotein that acts as a coreceptor for transforming growth factor- $\beta$. Endoglin is highly expressed on cellular membranes of the vascular endothelium and on the syncytiotrophoblast [37-40]. It is involved in angiogenesis and has a major role in maintaining vascular tone $[41,42]$. Its soluble circulating form (sEng), produced through the proteocleavage of the placental membrane-bound form, is an antiangiogenic factor implicated in the pathogenesis of PE and HELLP syndrome [22]. Placental tissue expression of sEng is upregulated in patients with PE.

Plasmapheresis is not a standard treatment for APSrelated pregnancy complications [43] but it has been used successfully in pregnancies with APS [13-19]. The rationale is the removal of $\mathrm{aPl}$ and proinflammatory and -coagulatory markers, adhesion molecules, vasopressive factors, and atherogenic lipoproteins. The goal is to improve maternal endothelial function, prevent thrombosis, and increase placental perfusion with consecutive impaired trophoblast invasiveness and placentation. This hypothesis has been recently confirmed in a pilot study of nine preterm preeclamptic women [9]. In our patient, the immediate response and the evident removal of endoglin support the use of plasmapheresis for treatment of pregnancies with PE, especially in early gestation, as well as pregnancies with APS to improve obstetric outcome.

Bontadi et al. reported a significant therapeutic decrease of aPl-antibodies (ACLA and B2-glycoprotein) in 3 women successfully treated with plasma exchange and immunoadsorption as a second-line therapy in APS [15]. A retrospective European multicentre study found that certain pregnant women with APS (thrombosis and triple antiphospholipid autoantibody positivity) who received additional treatment including apheresis had a significantly higher live birth rate than controls receiving conventional therapy alone [19].

Thadhani et al. demonstrated the concept of removing pathogenic circulating factors with plasma exchange in 2011. The authors treated five women with very preterm PE with dextran sulfate cellulose apheresis. This reduced circulating sflt-1 levels and proteinuria in a dose-dependent manner and stabilized blood pressure without apparent adverse events. sflt-1 plasma levels decreased by $20 \%-30 \%$ [8]. Blaha et al. showed a significant decrease of soluble endoglin after extracorporeal elimination in 11 patients with severe familial disorders of lipid metabolism. They suggested that endoglin might serve as a marker for evaluation of treatment efficacy [44].

Plasmapheresis may be a therapeutic option particularly for pregnancies with early-onset preeclampsia. Only a few authors have described plasmapheresis as treatment for PE, mostly in case reports with diverse success [45-47].

The patient described in the present report showed a decrease of mean sflt-1 levels 1 day after plasmapheresis and a decrease of mean sflt-1 levels until $24+5$ weeks, suggesting that treatment with LMWH itself might not influence the circulatory levels of sflt-1 (Yinon et al.). Additionally the authors noted a rerise of sflt-1, especially after the fifth course $(24+$ 5 weeks of gestation). These changes of sflt-1 levels might be associated with the development of placental abruption [32].

To our knowledge, this is the first report of a significant decrease of endoglin after plasmapheresis in a pregnant woman with APS and early-onset preeclampsia and placental abruption. However, several therapeutical approaches such as prophylactic apheresis or IVIG beginning early in the pregnancy, rather than starting at the onset of complications, could be an optional treatment, also to prevent complications of obstetric APS, including preeclampsia.

\section{Conflict of Interests}

The authors declare that there is no conflict of interests regarding the publication of this paper.

\section{References}

[1] S. Miyakis, M. D. Lockshin, T. Atsumi et al., "International consensus statement on an update of the classification criteria 
for definite antiphospholipid syndrome (APS)," Journal of Thrombosis and Haemostasis, vol. 4, no. 2, pp. 295-306, 2006.

[2] C. W. Redman and I. L. Sargent, "Latest advances in understanding preeclampsia," Science, vol. 308, no. 5728, pp. 1592-1594, 2005.

[3] R. J. Levine, S. E. Maynard, C. Qian et al., "Circulating angiogenic factors and the risk of preeclampsia," The New England Journal of Medicine, vol. 350, no. 7, pp. 672-683, 2004.

[4] G. Girardi, J. Berman, P. Redecha et al., "Complement C5a receptors and neutrophils mediate fetal injury in the antiphospholipid syndrome," Journal of Clinical Investigation, vol. 112, no. 11, pp. 1644-1654, 2003.

[5] V. M. Holers, G. Girardi, L. Mo et al., "Complement C3 activation is required for antiphospholipid antibody-induced fetal loss," The Journal of Experimental Medicine, vol. 195, no. 2, pp. 211-220, 2002.

[6] J. Alijotas-Reig, "Treatment of refractory obstetric antiphospholipid syndrome: the state of the art and new trends in the therapeutic management," Lupus, vol. 22, no. 1, pp. 6-17, 2013.

[7] S. Ornaghi and M. J. Paidas, "Upcoming drugs for the treatment of preeclampsia in pregnant women," Expert Review of Clinical Pharmacology, vol. 7, no. 5, pp. 599-603, 2014.

[8] R. Thadhani, T. Kisner, H. Hagmann et al., "Pilot study of extracorporeal removal of soluble fms-like tyrosine kinase 1 in preeclampsia," Circulation, vol. 124, no. 8, pp. 940-950, 2011.

[9] Y. Wang, A. K. Walli, A. Schulze et al., "Heparin-mediated extracorporeal low density lipoprotein precipitation as a possible therapeutic approach in preeclampsia," Transfusion and Apheresis Science, vol. 35, no. 2, pp. 103-110, 2006.

[10] B. Shenkman and Y. Einav, "Thrombotic thrombocytopenic purpura and other thrombotic microangiopathic hemolytic anemias: diagnosis and classification," Autoimmunity Reviews, vol. 13, no. 4-5, pp. 584-586, 2014.

[11] A. Fyfe-Brown, G. Clarke, K. Nerenberg, S. Chandra, and V. Jain, "Management of pregnancy-associated thrombotic thrombocytopenia purpura," American Journal of Perinatology Reports, vol. 3, no. 1, pp. 45-50, 2013.

[12] F. Jin, M. Cao, Y. Bai, Y. Zhang, Y. Yang, and B. Zhang, "Therapeutic effects of plasma exchange for the treatment of 39 patients with acute fatty liver of pregnancy," Discovery Medicine, vol. 13, no. 72, pp. 369-373, 2012.

[13] D. O. El-Haieg, M. F. Zanati, and F. M. El-Foual, "Plasmapheresis and pregnancy outcome in patients with antiphospholipid syndrome," International Journal of Gynecology and Obstetrics, vol. 99, no. 3, pp. 236-241, 2007.

[14] G. Frampton, J. S. Cameron, M. Thom, S. Jones, and M. Raftery, "Successful removal of anti-phospholipid antibody during pregnancy using plasma exchange and low-dose prednisolone," The Lancet, vol. 2, no. 8566, pp. 1023-1024, 1987.

[15] A. Bontadi, A. Ruffatti, P. Marson et al., "Plasma exchange and immunoadsorption effectively remove antiphospholipid antibodies in pregnant patients with antiphospholipid syndrome," Journal of Clinical Apheresis, vol. 27, no. 4, pp. 200-204, 2012.

[16] M. Bortolati, P. Marson, S. Chiarelli et al., "Case reports of the use of immunoadsorption or plasma exchange in highrisk pregnancies of women with antiphospholipid syndrome," Therapeutic Apheresis and Dialysis, vol. 13, no. 2, pp. 157-160, 2009.

[17] S. Kobayashi, N. Tamura, H. Tsuda, C. Mokuno, H. Hashimoto, and S. Hirose, "Immunoadsorbent plasmapheresis for a patient with antiphospholipid syndrome during pregnancy," Annals of the Rheumatic Diseases, vol. 51, no. 3, pp. 399-401, 1992.
[18] A. Ruffatti, P. Marson, V. Pengo et al., "Plasma exchange in the management of high risk pregnant patients with primary antiphospholipid syndrome. A report of 9 cases and a review of the literature," Autoimmunity Reviews, vol. 6, no. 3, pp. 196-202, 2007.

[19] A. Ruffatti, E. Salvan, T. D. Del Ross et al., "Treatment strategies and pregnancy outcomes in antiphospholipid syndrome patients with thrombosis and triple antiphospholipid positivity. A European multicentre retrospective study," Thrombosis and Haemostasis, vol. 112, no. 4, pp. 727-735, 2014.

[20] T. Bosch, "Therapeutic apheresis-state of the art in the year 2005," Therapeutic Apheresis and Dialysis, vol. 9, no. 6, pp. 459468, 2005.

[21] S. Venkatesha, M. Toporsian, C. Lam et al., "Soluble endoglin contributes to the pathogenesis of preeclampsia," Nature Medicine, vol. 12, pp. 642-649, 2006.

[22] R. J. Levine, C. Lam, C. Qian et al., "Soluble endoglin and other circulating antiangiogenic factors in preeclampsia," The New England Journal of Medicine, vol. 355, no. 10, pp. 992-1005, 2006.

[23] H. Stepan, T. Krämer, and R. Faber, "Maternal plasma concentrations of soluble endoglin in pregnancies with intrauterine growth restriction," Journal of Clinical Endocrinology and Metabolism, vol. 92, no. 7, pp. 2831-2834, 2007.

[24] H. Masuyama, H. Nakatsukasa, N. Takamoto, and Y. Hiramatsu, "Correlation between soluble endoglin, vascular endothelial growth factor receptor-1, and adipocytokines in pre-eclampsia," Journal of Clinical Endocrinology and Metabolism, vol. 92, no. 7, pp. 2672-2679, 2007.

[25] A. Jeyabalan, S. McGonigal, C. Gilmour, C. A. Hubel, and A. Rajakumar, "Circulating and placental endoglin concentrations in pregnancies complicated by intrauterine growth restriction and preeclampsia," Placenta, vol. 29, no. 6, pp. 555-563, 2008.

[26] A. De Vivo, G. Baviera, D. Giordano, G. Todarello, F. Corrado, and R. D’Anna, "Endoglin, PlGF and sFlt-1 as markers for predicting pre-eclampsia," Acta Obstetricia et Gynecologica Scandinavica, vol. 87, no. 8, pp. 837-842, 2008.

[27] Y. N. Kim, D. S. Lee, D. H. Jeong, M. S. Sung, and K. T. Kim, “The relationship of the level of circulating antiangiogenic factors to the clinical manifestations of preeclampsia," Prenatal Diagnosis, vol. 29, no. 5, pp. 464-470, 2009.

[28] A. Reddy, S. Suri, I. L. Sargent, C. W. G. Redman, and S. Muttukrishna, "Maternal circulating levels of activin A, inhibin A, sFlt-1 and endoglin at parturition in normal pregnancy and pre-eclampsia," PLoS ONE, vol. 4, no. 2, Article ID e4453, 2009.

[29] S. Rana, S. A. Karumanchi, R. J. Levine et al., "Sequential changes in antiangiogenic factors in early pregnancy and risk of developing preeclampsia," Hypertension, vol. 50, no. 1, pp. 137142, 2007.

[30] C. J. Robinson and D. D. Johnson, "Soluble endoglin as a second-trimester marker for preeclampsia," American Journal of Obstetrics and Gynecology, vol. 197, no. 2, pp. 174.el-174.e5, 2007.

[31] J. H. Lim, S. Y. Kim, SoYeonPark et al., "Soluble endoglin and transforming growth factor- $\beta 1$ in women who subsequently developed preeclampsia," Prenatal Diagnosis, vol. 29, no. 5, pp. 471-476, 2008.

[32] C. Signore, J. L. Mills, C. Qian et al., "Circulating soluble endoglin and placental abruption," Prenatal Diagnosis, vol. 28, no. 9, pp. 852-858, 2008. 
[33] V. A. Rosenberg, I. A. Buhimschi, C. J. Lockwood et al., "Heparin elevates circulating soluble fms-like tyrosine kinase1 immunoreactivity in pregnant women receiving anticoagulation therapy," Circulation, vol. 124, no. 23, pp. 2543-2553, 2011.

[34] S. Sela, S. Natanson-Yaron, E. Zcharia, I. Vlodavsky, S. Yagel, and E. Keshet, "Local retention versus systemic release of soluble VEGF receptor-1 are mediated by heparin-binding and regulated by heparanase," Circulation Research, vol. 108, no. 9, pp. 1063-1070, 2011.

[35] T. Y. Carroll, M. J. Mulla, C. S. Han et al., "Modulation of trophoblast angiogenic factor secretion by antiphospholipid antibodies is not reversed by heparin," American Journal of Reproductive Immunology, vol. 66, no. 4, pp. 286-296, 2011.

[36] Y. Yinon, E. Ben Meir, L. Margolis et al., "Low molecular weight heparin therapy during pregnancy is associated with elevated circulatory levels of placental growth factor," Placenta, vol. 36, no. 2, pp. 121-124, 2015.

[37] S. Cheifetz, T. Bellon, C. Cales et al., "Endoglin is a component of the transforming growth factor-beta receptor system in human endothelial cells," The Journal of Biological Chemistry, vol. 267, no. 27, pp. 19027-19030, 1992.

[38] S. St-Jacques, M. Forte, S. J. Lye, and M. Letarte, "Localization of endoglin, a transforming growth factor-beta binding protein, and of CD44 and integrins in placenta during the first trimester of pregnancy," Biology of Reproduction, vol. 51, no. 3, pp. 405413, 1994.

[39] U. Raab, B. Velasco, P. Lastres et al., "Expression of normal and truncated forms of human endoglin," Biochemical Journal, vol. 339, no. 3, pp. 579-588, 1999.

[40] U. Raab, P. Lastres, M. A. Arévalo et al., "Endoglin is expressed in the chicken vasculature and is involved in angiogenesis," FEBS Letters, vol. 459, no. 2, pp. 249-254, 1999.

[41] S. E. Duff, C. Li, J. M. Garland, and S. Kumar, "CD105 is important for angiogenesis: evidence and potential applications," The FASEB Journal, vol. 17, no. 9, pp. 984-992, 2003.

[42] M. Toporsian, R. Gros, M. G. Kabir et al., "A role for endoglin in coupling eNOS activity and regulating vascular tone revealed in hereditary hemorrhagic telangiectasia," Circulation Research, vol. 96, no. 6, pp. 684-692, 2005.

[43] J. Schwartz, J. L. Winters, A. Padmanabhan et al., "Guidelines on the use of therapeutic apheresis in clinical practice-evidencebased approach from the Writing Committee of the American Society for Apheresis: the sixth special issue," Journal of Clinical Apheresis, vol. 28, no. 3, pp. 145-284, 2013.

[44] M. Blaha, M. Cermanova, V. Blaha et al., "Elevated serum soluble endoglin (sCD105) decreased during extracorporeal elimination therapy for familial hypercholesterolemia," Atherosclerosis, vol. 197, no. 1, pp. 264-270, 2008.

[45] M. L. Schwartz, "Possible role for exchange plasmapheresis with fresh frozen plasma for maternal indications in selected cases of preeclampsia and eclampsia," Obstetrics and Gynecology, vol. 68, no. 1, pp. 136-139, 1986.

[46] J. N. Martin Jr., K. G. Perry Jr., W. E. Roberts et al., "Plasma exchange for preeclampsia: II. Unsuccessful antepartum utilization for severe preeclampsia with or without HELLP syndrome," Journal of Clinical Apheresis, vol. 9, no. 3, pp. 155-161, 1994.

[47] A. J. F. d'Apice, L. L. Reti, R. J. Pepperell, K. F. Fairley, and P. Kincaid-Smith, "Treatment of severe pre-eclampsia by plasma exchange," The Australian and New Zealand Journal of Obstetrics and Gynaecology, vol. 20, no. 4, pp. 231-235, 1980. 


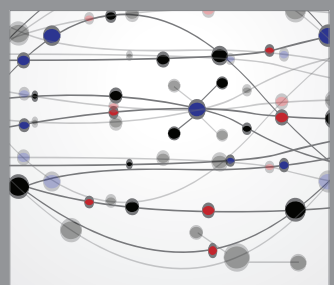

The Scientific World Journal
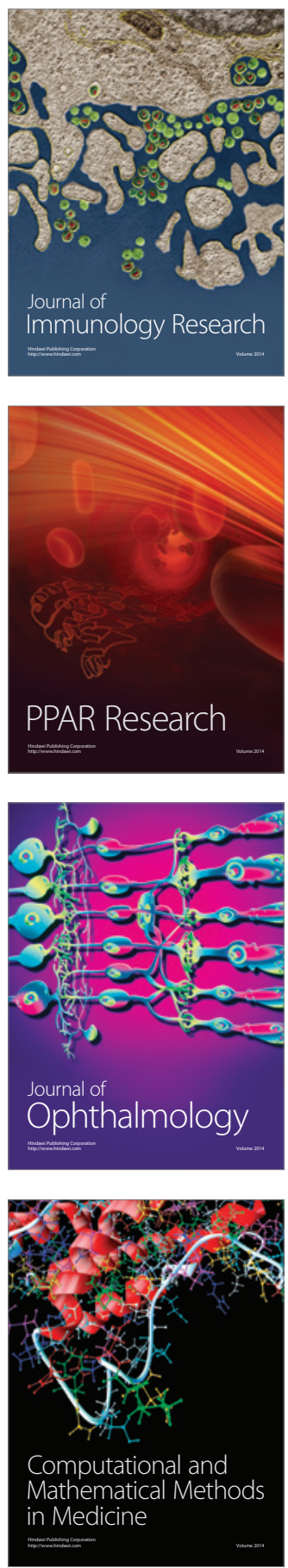

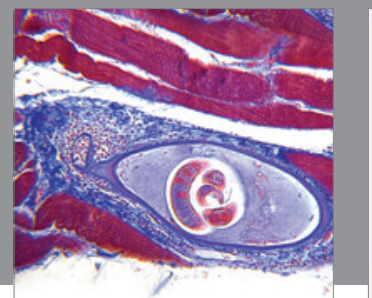

Gastroenterology

Research and Practice
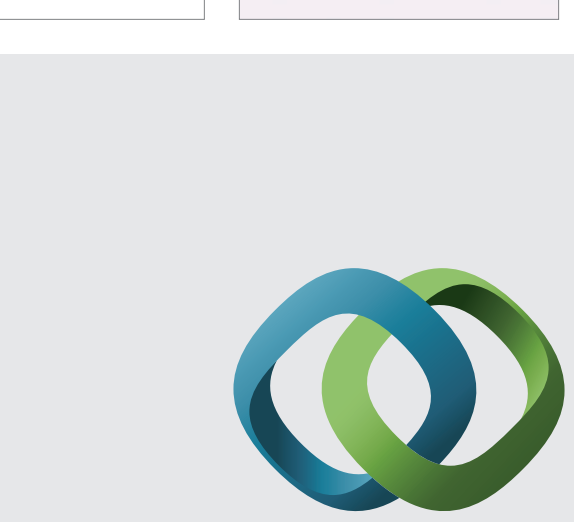

\section{Hindawi}

Submit your manuscripts at

http://www.hindawi.com
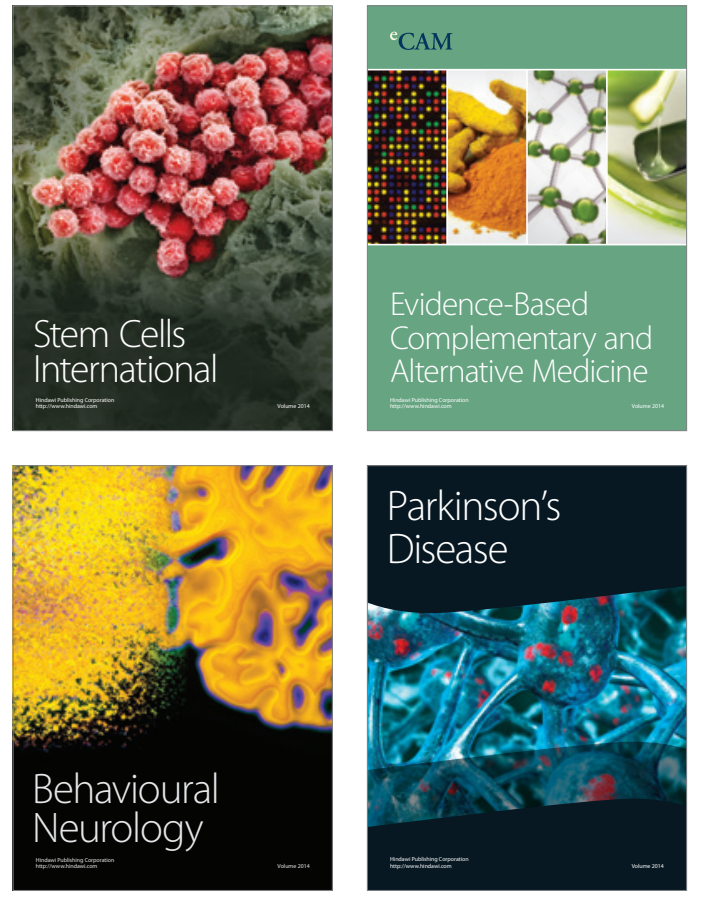
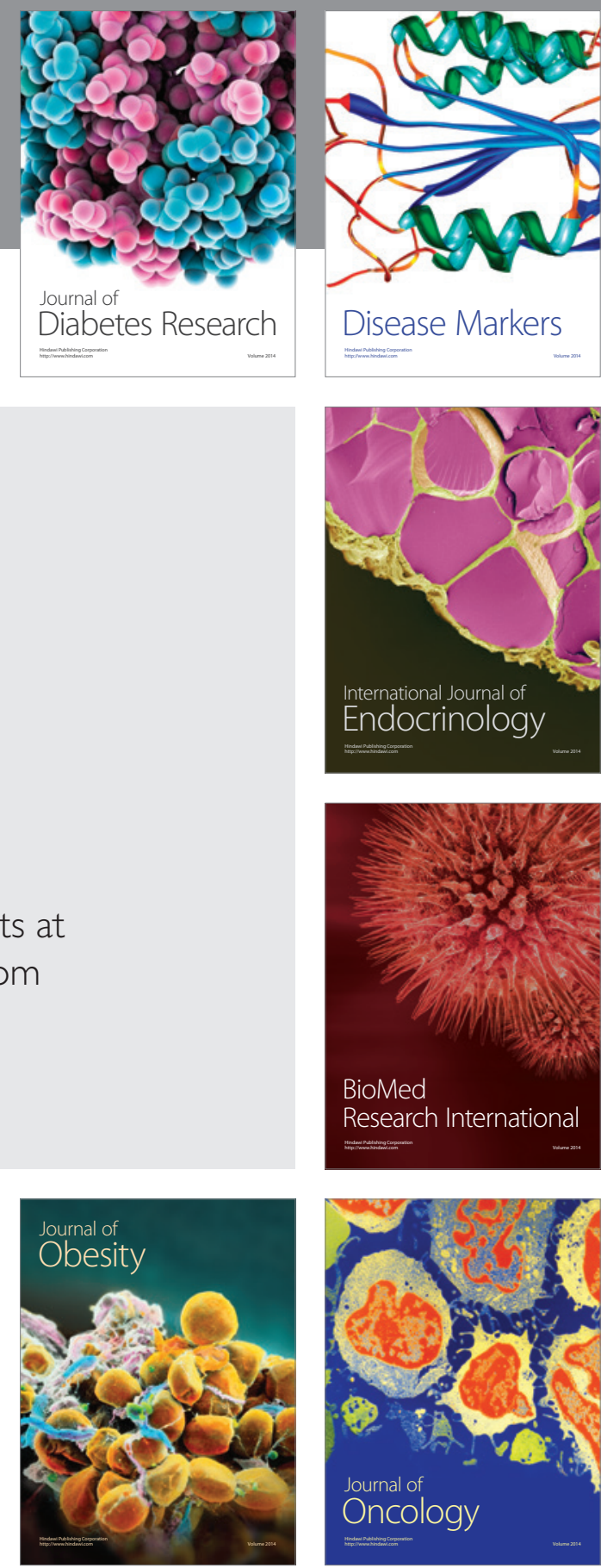

Disease Markers
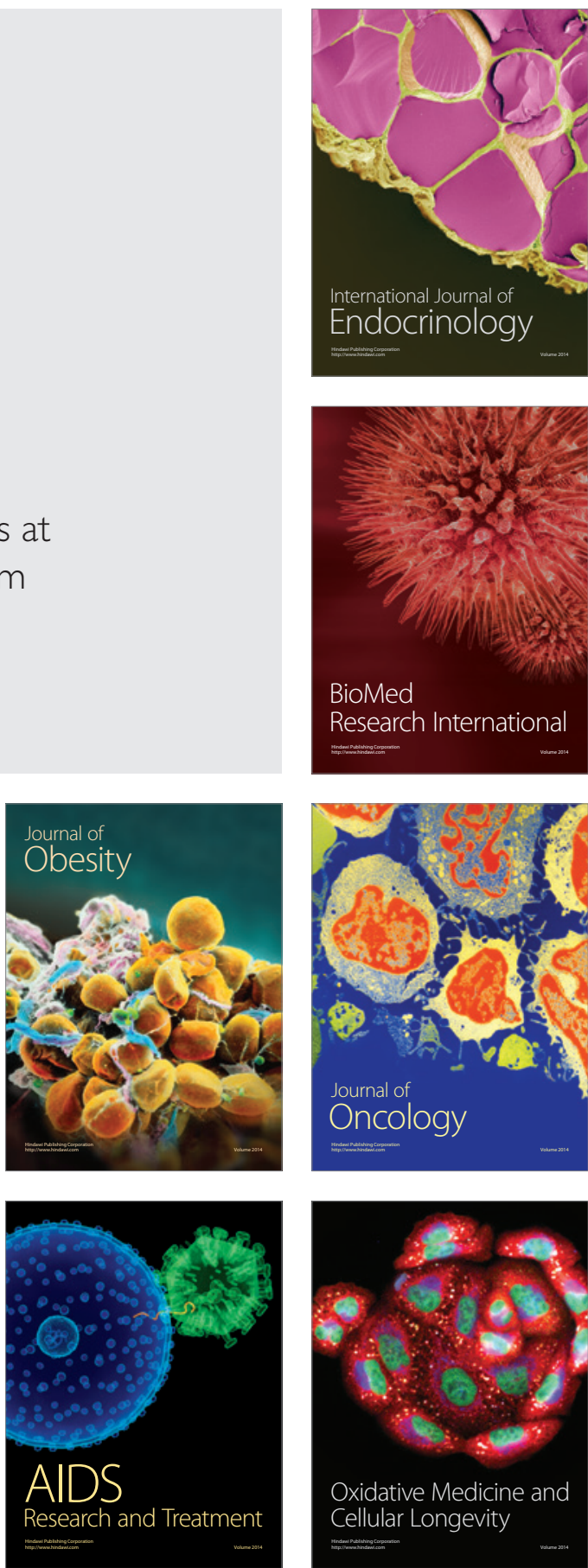